\title{
Effects of carrot powder intake after weaning on tumours in $\mathrm{APC}^{\mathrm{Min}}$ mice
}

\author{
M. Almqbel, C.J. Seal and K. Brandt \\ Human Nutrition Research Centre, School of Agriculture, Food and Rural Development, Newcastle University, \\ Newcastle upon Tyne, NE1 7RU, UK
}

Carrot contains several types of potentially beneficial bioactive compounds such as polyacetylenes, polyphenols and carotenes ${ }^{(1)}$. Mice with the $\mathrm{APC}^{\mathrm{Min}}$ mutation are a common model of cancer in the small intestine and colon, to study the role of diet on tumours ${ }^{(2)}$. A previous study showed a substantial reduction in number of visible tumours when mice were fed carrot-supplemented diet throughout their lifetime (including in utero) ${ }^{(3)}$. The main aim of the study was to investigate if the active substances in carrot would be able to reduce the growth of intestinal tumours in $\mathrm{APC}^{\mathrm{Min}}$ mice when the carrot treatment was started only after the fifth week (after weaning). After weaning at five weeks, the mice were genotyped and divided into different groups. Each group received powdered feed containing either $20 \%$ freeze-dried carrot powder or control (standard mouse) diet for 10 weeks before killing. The mice were autopsied and tumours $>1 \mathrm{~mm}$ in diameter were counted in 3 sections of the digestive tract: Proximal small intestine, Distal small intestine and Colon.

Feeding mice a diet containing $20 \%$ powdered carrots dramatically reduced the number of tumours $(\mathrm{P}=0.007)$, with no differences between sections of the intestine (Fig. 1). As for the weight of the mice, there were no significant differences between carrot or control feeding $(\mathrm{P}=0.492)$. This result indicates the possibility of using carrots in the diet or bioactive compounds derived from them to reduce the growth of tumours.

Tumours per section

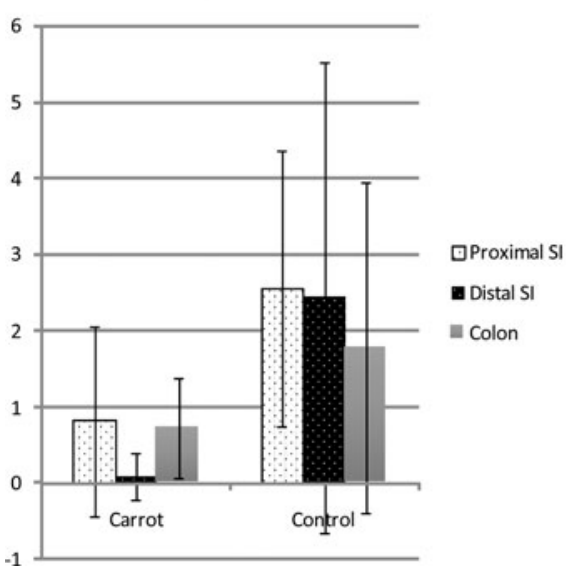

Total tumours

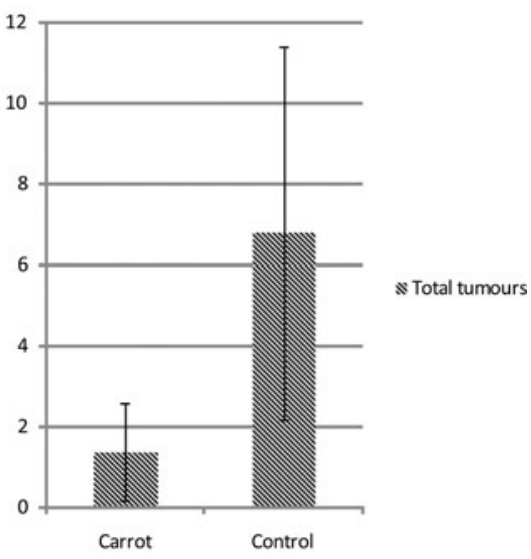

Fig.1. Tumours per section (left), and Total number of tumours (right) at 15 weeks in $\mathrm{APC}^{\mathrm{Min}}$ mice feed control $(\mathrm{N}=9)$ or $20 \%$ carrot powder diet $(\mathrm{N}=11)$ for 10 weeks. Error bars show Standard Deviation.

1. Zaini R, Brandt K, Clench MR, LeMaitre CL (2012) Anti-Cancer Agents Med Chem 12, 640-652.

2. Tamariello AE \& Milner JA (2010) J Nutr Biochem 21, 77-88.

3. Saleh H, Garti H, Carroll M and Brandt K (2013) Proc. Nutr. Soc 72 (OCE4): E183 